\title{
A importância do acolhimento e do aquecimento em grupos sem demanda no contexto da Justiça
}

\author{
The Importance of Welcoming and Warming up in Groups without \\ spontaneous demand in the context of Justice.
}

\section{La importancia de la acogida y del caldeamiento en grupos de hombres sin demanda en el contexto del sistema de Justicia}

\author{
Stela Dalva Abritta \\ Interpsi - e-mail: sdabritta@gmail.com \\ Fernanda Cunha Fontoura Roque \\ Interpsi - e-mail: fernandafontoura.r@gmail.com \\ Maria Eveline Cascardo Ramos \\ Interpsi - e-mail: evelinecascardo@yahoo.com.br
}

\begin{abstract}
Resumo
Este artigo apresenta aspectos da experiência de atendimento aos grupos de homens envolvidos em violência doméstica. Abordou-se parte dos resultados obtidos em quatro anos de intervenção socioterapêutica no contexto da Justiça. Foram ressaltados o aquecimento e o acolhimento nas etapas da sessão, no atendimento socioterapêutico e no processo grupal. Elegemos a metodologia psicodramática e o método de pesquisa-em-intervenção, realizando a análise compreensiva do vivido em cada grupo e a análise comparativa entre eles. Concluímos que nesses grupos, sobretudo os envolvidos em violência contra a mulher, o acolhimento e o aquecimento desempenham uma função importante no desenvolvimento de uma intervenção que favoreça o protagonismo dos sujeitos e o resgate da espontaneidade e adequação nas situações da própria vida.
\end{abstract}

Palavras-chave: Acolhimento. Aquecimento. Violência contra a mulher. Grupos. Justiça.

\section{Abstract}

This article presents aspects of the experience of counselling with groups of men involved in domestic violence. It addressed part of the results obtained during four years of social therapeutic intervention within the Justice system. Emphasis is placed on the welcoming and the warming up stages of the session, in the social therapeutic counselling and in the group process. The methodology used is psychodrama and the research-through-intervention method 
using comprehensive analysis of the life experiences of each group and the comparative analysis between groups. Finally, we conclude that, in groups of individuals referred to us by the Justice system, particularly the ones who deal with violence against women, the welcoming and the warming up have an important function in the process of intervention promoting the protagonism of the individuals and the rescue of spontaneity and adequate responses to the situations of their own lives.

Keywords: Welcoming. Warming-up. Violence against women. Groups. Justice.

\section{Resumen}

Este artículo presenta aspectos de la experiencia de atendimiento con grupos de hombres implicados en la violencia doméstica. Se aborda una parte de los resultados obtenidos en los cuatro años de intervención social terapéutica en el contexto del sistema de justicia. Son destacadas la acogida y el caldeamiento en las etapas de la sesión, el proceso de atendimiento social terapéutico y el proceso del grupo. La metodología utilizada es el psicodrama y el método de investigación intervención utilizando el análisis comprensivo del vivido en cada grupo y el análisis comparativo entre ellos. Finalmente, se concluye que, en grupos de individuos encaminados por la justicia, particularmente los que se ocupan de la violencia contra la mujer, la acogida y el caldeamiento tienen una función importante en el proceso de intervención, promoviendo el protagonismo de las personas y el rescate de la espontaneidad y las respuestas adecuadas a las situaciones de sus vidas.

Palabras-clave: Acogida. Caldeamiento. Violencia contra la mujer. Grupos. Justicia.

\section{INTRODUÇÃO}

O tema central deste artigo é a percepção de que o acolhimento é fundamental para a relação terapêutica, psicoterapêutica ou socioterapêutica e o aquecimento como fase inicial para o desenvolvimento da sessão e do processo grupal.

A forma especial de receber a pessoa, com compreensão, estímulo e qualificação, caracteriza o bom acolhimento e nos faz acreditar que esses atributos passam a permear as relações desenvolvidas nos grupos. Nos trabalhos sem demanda espontânea, como os socioterapêuticos, tem-se visto que o acolhimento que valoriza a compreensão do indivíduo e de seu comportamento viabiliza o conhecimento da qualidade de suas relações na família, o locus da agressividade denunciada (OSÓRIO, 2002).

A referência para este artigo são os grupos de homens envolvidos em violência doméstica; entretanto, a reflexão não se atém apenas à demanda desses homens, mas de um sem-número de pessoas que estão em grupos ligados à justiça, à assistência ou outros grupos não inseridos em um projeto de mudança.

Pensando na realidade conflituosa que permeia as famílias em situação de violência, sobretudo violência contra a mulher, foi realizada uma intervenção socioterapêutica inscrita na prática demandada com a implementação da Lei 11.340/06 (BRASIL, 2006).

Ao desenvolver os trabalhos com grupos, Moreno $(1974 ; 1994 \mathrm{a} ; 2008)$ destacou a criatividade e a responsabilidade mútua e recíproca que favorecem o bem-estar grupal, individual e, por extensão, social. Assim, os membros do grupo são levados a 
Abritta, Stela Dalva; Roque, Fernanda Cunha Fontoura; Ramos, Maria Eveline Cascardo. A importância do acolhimento e do aquecimento em grupos sem demanda no contexto da Justiça

compreenderem-se implicados na atuação e no processo (MORENO, 1974).

Atento a todas as peculiaridades das famílias envolvidas com violência doméstica, torna-se cada vez mais perceptível a importância de focar o atendimento nos autores como política de enfrentamento a essa violência. Ou seja, a partir da formação desses grupos como conscientes da responsabilidade recíproca, possíveis de cooperar entre si e cooperar com esse objetivo maior, tece-se um espaço para o nós (homens e mulheres), no qual podem estar juntos no enfrentamento à violência.

Nesse trabalho, empregou-se a abordagem psicodramática que busca dar voz ao outro por meio da ação com recursos para quebrar o estagnado e o estereotipado, promovendo novas respostas.

\section{ABORDAGEM PSICODRAMÁTICA E A INTERVENÇÃO SOCIOTERAPÊUTICA}

A abordagem psicodramática, sua epistemologia, seus métodos e suas técnicas têm importantes contribuições no trabalho com grupos encaminhados pela justiça. No atendimento socioterapêutico, o protagonista é sempre o grupo, o tema é apenas um veículo, mas o maior recurso é a interação grupal. A intervenção se dá a partir do papel que representa a dificuldade do grupo, atentando-se sempre à complementaridade dos papéis.

Dois fatores importantes na terapêutica desses grupos e das relações que favorecem entrar na emoção são o acolhimento e o aquecimento. $\mathrm{O}$ acolhimento é uma postura que permeia toda a atuação profissional com foco na construção e na manutenção do vínculo, bem como implica uma escuta qualificada que emprega o movimento empático para favorecer a troca subjetiva e a liberdade de expressão. Já o aquecimento é uma etapa importante do preparo profissional, da formação do grupo, da sessão sociodramática, do início da ação e do processo socioterapêutico.

Ao pensar uma filogenia conceitual do acolhimento, apresenta-se o rapport, um elemento que tem por objetivo favorecer a comunicação. Estabelecer rapport é tecer uma relação pautada pela empatia (ZIMERMAN, 2004), com atmosfera de confiabilidade e veracidade. $O$ que não significa que serão aceitas todas as atitudes, comportamentos e opiniões da outra pessoa, mas podem ser ouvidas com compreensão, interesse e respeito genuíno. Enquanto o rapport estará mais presente nas entrevistas iniciais, o acolhimento é uma postura profissional ampla e permanente.

A ontogenia conceitual do acolhimento apresenta-o como um elemento do processo grupal que será mantido do início até o final da intervenção. Acolher significa responsabilizar-se por um cuidado, oferecer um olhar e uma escuta com a possibilidade de construção do vínculo que visa garantir suporte ao outro em todas as suas possibilidades e manifestações. O terapeuta que acolhe precisa transcender suas conservas culturais para estar aberto àquilo que cada sujeito traz consigo, suas histórias, seus sentimentos, suas emoções e seus significados atribuídos ao vivido (MORENO, 1974).

No psicodrama, compreende-se o acolhimento a partir do Encontro, quando Moreno referiu-se à postura do terapeuta empregando o conceito Eu-Tu de Buber (2006). Assim, a estabilidade do relacionamento que promove mudanças depende da força da coesão télica que atua entre o terapeuta e o sujeito, o terapeuta e o grupo (MORENO, 1983).

A demanda do sujeito é um fator importante para favorecer a mudança; todavia, não é possível formular uma demanda sem o vínculo de confiança e não se cria o vínculo sem o acolhimento adequado. É preciso acolher para favorecer o vínculo e então fazer surgir a formulação e o desenvolvimento da demanda que possibilitará as transformações desejadas.

Todo esse processo é iniciado com o aquecimento do profissional, do sujeito, do 
grupo, da ação e do processo grupal. Há uma familiaridade fértil entre o acolhimento e o aquecimento. A ontogenia conceitual do aquecimento terá membranas de acolhimento que nutre, estabelece contato, intercomunica e mantêm o clima ideal do aquecimento. Ambos se favorecem e se complementam, se nutrem na mesma medida em que se ampliam e geram frutos.

Inspirados no que propôs Moreno (1975) e Zerka (MORENO; MORENO, 2006), outros autores (FONSECA FILHO, 1980; PERAZZO, 1994; MONTEIRO, 1994; ALMEIDA, 1998; DAVOLI, 1999, SANTOS e CONCEIÇÃO, 2014) já abordaram a importância do aquecimento como desencadeador da espontaneidade, busca do ser criativo e espontâneo e guia que conduz ao encontro $\mathrm{Eu}-\mathrm{Tu}$.

O aquecimento é formado por um conjunto de procedimentos indispensáveis na preparação de um organismo para a ação "na medida em que este se esforça no sentido de um ato" (MORENO, 1975, p. 106). O aquecimento favorece a construção de um campo relaxado no qual será possível emergir com delicadeza e suavidade as questões emocionais e afetivas, presentes na história de cada um. O aquecimento como etapa do processo, ou seja, na fase de trabalhar o $E u$, será a construção de um espaço de escuta, reflexão e compartilhamento, sem julgamento e sem censura, que favorece que os participantes falem de si (RAMOS, 2013). À medida que se percebem recebidos e aceitos, os participantes podem passar para outras fases de percepção do outro, percepção do grupo e responsabilização pelas relações interpessoais que estabelecem e mantêm.

Na sessão psicodramática, métodos de aquecimento preparatório são utilizados para estimular o corpo para atitudes e atuações espontâneas (MORENO, 1975), ele, contudo, se faz necessário não só no início da sessão ou do processo grupal, mas durante esses processos, no momento em que surge alguma dificuldade para avançar no processo ou na ação.

Seguindo essa metodologia, há registros de que o trabalho em grupos tem promovido amplas mudanças no comportamento desses homens, pois foi registrado um número muito pequeno de reincidência (FONTOURA, 2009, 2012; RAMOS, 2008, 2013; RAMOS, SANTOS E DOURADO, 2009, RAMOS E FONTOURA, 2010; ABRITTA, 2010; ABRITTA e SILVA, 2010).

\section{METODOLOGIA DE PESQUISA}

A trajetória metodológica deste trabalho inscreve-se no âmbito da epistemologia qualitativa, elegendo como metodologia a psicodramática e o método de pesquisa-emintervenção, recomendado para o Sociodrama.

A inserção do pesquisador como coparticipante da investigação em uma posição criativa que constrói significados situados é o diferencial que traduz um aspecto constitutivo da pesquisa qualitativa (MARRA e FLEURY, 2008). Compreende-se a metodologia sociodramática como uma pesquisa-em-intervenção, uma vez que os terapeutas intervêm na direção do trabalho e na facilitação da análise do material compartilhado, as situações e os dados contextuais e relacionais são fornecidos pelo grupo, e a pesquisa e a intervenção estão concomitantes.

\section{POPULAÇÃO ATENDIDA}

No percurso metodológico, reuniram-se os dados e os registros dos grupos coletados no período de quatro anos. Os trabalhos que se seguem foram realizados no contexto da justiça pela parceria do Instituto de Pesquisa e Intervenção Psicossocial (Interpsi) inicialmente 
com a Central de Medidas Alternativas (Cema) e depois com a Promotoria de Justiça. Os participantes foram comunicados e consentiram, por meio de Termo de Consentimento Livre e Esclarecido, acerca da utilização dos dados coletados durante as intervenções para fins de estudo e publicação.

Para a formação dos grupos em geral, realizamos entrevistas de acolhimento individual, exceto no primeiro grupo, que teve um acolhimento geral e contou com presença de uma advogada do Setor de Medidas Alternativas (Sema).

As intervenções semanais, com enfoque socioterapêutico, tiveram duração de uma hora e trinta minutos e perfizeram um total de 16 encontros. A equipe era composta por dois ou três psicólogos que se revezavam na função de diretor e ego-auxiliar. Os registros eram realizados por ambos, imediatamente após os encontros.

Ao todo foram 28 participantes (6 do Grupo I, 15 do Grupo II e 7 do Grupo III), na faixa etária de 22 a 64 anos, de analfabeto funcional a nível superior completo, alguns desempregados, outros com profissões liberais, prestadores de serviços gerais e funcionário público de nível superior. Todos estavam cumprindo medida alternativa por agressão dirigida à mulher, filha ou companheira. $\mathrm{O}$ grupo era composto por moradores da própria cidade onde se localizava a Promotoria e por pessoas do entorno da região.

\section{ANÁLISE DO PROCESSO GRUPAL}

\section{GRUPO I}

O primeiro contato que o grupo teve com os psicólogos foi em uma reunião coletiva realizada por um operador da justiça. Não houve entrevista de acolhimento individual.

Os homens chegaram intimidados, amedrontados, revoltados por não terem tido oportunidade de falar na audiência, indignados com o rótulo de agressores e também por terem sido apontados como únicos responsáveis pela situação de violência.

De início, cabe destacar a diferença de humor entre os grupos em função das diferentes formas de acolhimento realizadas para o atendimento socioterapêutico. O primeiro encontro, o de acolhimento aos participantes, foi conduzido pelo operador da justiça. O grupo não se sentiu aceito nem compreendido, o que ampliou suas resistências. Os psicólogos precisaram dedicar mais atenção a esclarecer seu papel, os elementos que formam sua atuação ética, os objetivos da intervenção e a independência dessa atuação da psicologia em relação à atuação tradicional da justiça. Só então os participantes se permitiram iniciar uma relação de confiança com os terapeutas.

$\mathrm{O}$ aquecimento proposto pelo psicodrama na construção de um campo relaxado favorece o desenvolvimento da proposta e a conscientização dos participantes sobre os próprios atos. Fora do campo relaxado, eles ficam presos aos estereótipos de gênero e às justificativas para a ação violenta. Ao contrário, quando bem aquecidos, relaxados, sentem-se à vontade e entregam-se à percepção real do vivido e à flexibilidade necessária para a modificação da realidade.

Nos aquecimentos desenvolvidos nos encontros com os grupos, criam-se meios de favorecer a disposição de cada um para ouvir o outro e tornar-se, em seguida, capaz de responder às suas manifestações.

Note-se que a etapa do aquecimento dos encontros foi particularmente importante nesse grupo, pois a espontaneidade se mostrava coartada pelo fato de o grupo não ter se sentido acolhido no primeiro encontro.

\section{GRUPO II}


Abritta, Stela Dalva; Roque, Fernanda Cunha Fontoura; Ramos, Maria Eveline Cascardo. A importância do acolhimento e do aquecimento em grupos sem demanda no contexto da Justiça

As entrevistas de acolhimento individual para a formação do grupo e o primeiro encontro foram realizadas pela mesma equipe de psicólogos, sem a presença de representantes da justiça. Todavia, o espaço físico não possibilitava privacidade nem infraestrutura. A porta não trancava e as janelas tinham os vidros quebrados. Não havia banheiros, nem água potável. Por essas razões, a equipe mobilizou-se, em parceria com a promotoria, para realizar os encontros, considerando as necessidades básicas e humanas dos sujeitos.

As condições do espaço físico denunciavam um tipo de exclusão e punição simbólica. As medidas de transformação dessas condições e as melhorias do espaço físico foram percebidas pelos participantes como atenção e respeito a eles e influenciaram positivamente na relação de confiança entre todos.

Nesse grupo, foram acolhidos 17 homens, mas 15 permaneceram até o último encontro. Em um dos últimos encontros, receberam a visita da Promotora de Justiça. Nesse momento, a presença dela pôde ser compreendida como altamente importante e significativa para todos os participantes, pois se sentiram ouvidos e valorizados em suas questões pessoais, não só pelos profissionais da Psicologia, mas também pelos operadores da justiça. Durante os encontros, uma das queixas referia-se à falta de oportunidade para expressar suas narrativas acerca do vivido, os participantes sentiam que não tinham direito à fala diante das autoridades. Naquele encontro, esse sentimento e essa percepção puderam ser ressignificados por meio da escuta adequada da Promotora.

Nesses dois grupos ficou evidenciado o sentido atribuído à presença das operadoras da justiça em três fatores: o momento, as concepções e o convite. Quanto ao momento em que entraram para falar com os participantes, a Promotora, presente no Grupo II, acolheu-os nas angústias pela discriminação e pelo rótulo de bandido, dado pela sociedade e pela justiça, e ainda os orientou e esclareceu suas dúvidas em um ambiente relaxado, favorecendo que fossem escutados.

É importante registrar que a concepção que essa Promotora trouxe para o Grupo II acerca da violência contra a mulher foi ouvida e entendida, porque houve respeito ao grupo como sujeito. O tempo e o caminho relacional percorrido falam da habilidade de acolhimento e estabelecimento do rapport necessário ao trabalho.

Quanto às concepções, é importante que, com essa parceria, tanto os operadores da justiça quanto os psicólogos que realizam a intervenção tenham sintonia no entendimento ampliado para além do fato e no olhar que lançam aos sujeitos, considerando seu contexto familiar e social. No primeiro caso, a advogada concebia a violência contra a mulher como unilateral, e, portanto, os homens eram generalizados como os únicos responsáveis pelos conflitos que culminavam em ação violenta. No segundo grupo, a promotora percebia a violência como fenômeno relacional e acreditava na capacidade de os sujeitos promoverem mudanças em suas vidas.

\section{GRUPO III}

Foram acolhidos 12 homens; contudo, apenas seis participaram dos encontros até o final, os quais demonstravam grande interesse pelos temas abordados e a construção de novos aprendizados.

No período de atendimento desse grupo, houve uma tentativa de eliminar o programa de atenção aos ofensores, trocando-o pelo julgamento, sem transação penal. Alguns operadores da justiça, nos corredores da promotoria, chegavam a expressar claramente a descrença na transformação do comportamento desses homens, o que implicava aplicar, prioritariamente, as medidas punitivas tradicionais. Parece que essas posições geraram na 
equipe administrativa uma expectativa de que, a qualquer momento, esse trabalho de intervenção socioterapêutica poderia ser eliminado da rotina da promotoria, o que extinguiria as ações de contribuição com os participantes. Pode-se dizer que essas posições, somadas à falta de lugar próprio para funcionamento, foram intercorrências que influenciaram negativamente na disposição dos participantes, pois cada encontro poderia ser o último.

Entretanto, mesmo com essas intercorrências foi possível dar continuidade ao grupo, foi construído um espaço grupal e dramático, no qual os participantes puderam ser recebidos com o objetivo de favorecer suas transformações. A ação sociodramática, como vimos neste e em outros trabalhos, enriquece a prática e a pesquisa nesse contexto. No trabalho com esses grupos de homens, a abordagem psicodramática, sua epistemologia, seus métodos e suas técnicas têm importantes contribuições. Além de seu princípio de inclusão, que busca dar voz a todos por meio da ação e de seus recursos para quebrar o estagnado e o estereotipado, promovendo novas respostas, o psicodrama é uma modalidade que favorece o aspecto vivencial. À medida que trata os conflitos humanos na ação, reproduzindo o cenário em que esses conflitos ocorreram e com os recursos de concretização da dramatização, o psicodrama cria um espaço terapêutico que usa a vida como modelo, com todas as suas nuances e seus detalhes. (MORENO e MORENO, 2006). Nesse espaço, ficam mais visíveis as possibilidades de construções e desconstruções de ideias e atitudes, bem como o desenvolvimento das mudanças necessárias para o encontro consigo mesmo, com o outro e com a própria vida.

Essa intervenção é ainda potencializada por ocorrer em grupo. Como vimos, o psicodrama compreende o grupo como um sistema vivo em constante transformação, constituído de uma força interna que favorece a troca de experiências e facilita a quebra de resistências dos participantes, permitindo a construção de espaços para emergirem as demandas que dão sentido à intervenção (MORENO, 2008). Desse modo, os homens identificam aspectos em comum, criam vínculos e, dentro do grupo, constroem as possibilidades para a resolução dos conflitos.

A participação do sujeito no grupo e sua atuação o leva a perceber a razão, a intenção e o alcance do que faz (RAMOS, 2008) e, o mais importante, possibilita que identifique os sentimentos presentes em seus atos. Uma vez que o protagonista entra na emoção vivida no "aqui e agora", torna-se capaz de transformar-se principalmente pela descoberta de emoções e sentimentos presentes em suas ações e suas relações.

Ao desenvolver a Sociatria, Moreno (1994b) explicitou que essa nova ciência objetivava, sobretudo, formar grupos livres e empoderados que pudessem seguir sem o auxílio da Sociatria ou da psiquiatria. Por essa razão, àquela época, Moreno já lançava mão dos métodos psicodramáticos e sociodramáticos para realizar a terapia dos grupos com vistas à promoção da saúde social da humanidade.

Dessa forma, assim como noticiou Ramos (2008), os materiais trabalhados nesses grupos possibilitaram esclarecer as situações e proporcionar reflexões que levaram os sujeitos a se sentir capaz de construir estratégias para resolver os problemas que enfrentam.

\section{EM CONCLUSÃO E ABERTURA}

Esses grupos nos mostram a diferença da produção geral dos participantes e apontam para a dificuldade proveniente dos sentimentos de rejeição, exclusão e incompreensão sofridas por eles no momento em que devia ser de receptividade e entendimento. A análise mais ampla indica que o acolhimento favorece a confiança no grupo e a liberação da 
espontaneidade, o que está intimamente ligado ao bem-estar e à prontidão para a ação e a percepção dos diferentes aspectos das relações.

No contexto da justiça, esses sujeitos chegam em condição de discriminação social e judicial marcados por um olhar que os rotula pelo desvio e pela agressão, o que pode dificultar o acolhimento no início da triagem e na entrevista inicial, momento em que se ocorre a importante etapa da formação do grupo. Todavia, a postura em acolher favorece a construção do vínculo, do campo relaxado e o aquecimento para ação.

$\mathrm{Na}$ maioria dos contextos, as interações que incluíram violências receberam respostas violentas ou punitivas que dizem aquilo que não se deve fazer, mas tendem a manter o mesmo campo tenso que as gerou. Em outra via, as respostas de acolhimento introduzem possibilidades de intervenção e ação, favorecendo a percepção de si mesmo e a construção do que fazer e como atuar na própria vida, desde o modelo que o próprio grupo oferece.

Portanto, a forma assídua, presente, cuidadosa e respeitosa dispensada ao grupo transmitirá respeito e compromisso. Assim sendo, pelo princípio de generalização, os participantes podem experimentar relações diferentes, transformar-se nessas relações e estender esse novo modo de se relacionar para modificar o modo de interação, nesse caso violento, que de tão recorrente, desde as heranças transgeracionais, tornou-se habitual.

Também faz parte do acolhimento e do aquecimento, o cuidado com o espaço físico disponibilizado para o desenvolvimento do trabalho, que deverá ser um local apropriado, capaz de oferecer segurança, conforto e privacidade, favorecendo o tratamento mais cuidadoso das questões que surgem no grupo.

Vale ressaltar que acolhimento e aquecimento são fenômenos interdependentes e muito próximos em sua qualidade, pois os dois significam movimentos de aceitação e empatia necessários à evolução da relação terapêutica.

Emprega-se a empatia como ferramenta terapêutica que permite que se estabeleça um tipo de troca subjetiva que, mesmo sem a mediação da fala, favorece a liberdade de expressão. Os trabalhos desenvolvidos pela equipe evidenciaram a importância da escuta qualificada no acolhimento que transcende questões superficiais e aparentes e também permite uma configuração capaz de mergulhar na subjetividade e na particularidade de cada um, de modo que as pessoas tragam suas experiências anteriores em campo apropriado para a transformaação.

\section{REFERÊNCIAS}

ABRITTA, S. D. Psicologia e justiça: uma parceria profícua. 6 mai. 2012. 40 p. Monografia de especialização em Psicodrama - Pontifícia Universidade Católica de Goiás e Centro de Psicodrama de Brasília. Brasília, 2012.

; SILVA, N. L. P. Violência velada e revelada: um relato de experiência com um grupo de homens. Psicologia IESB, América do Norte, 2, ago. 2010. Disponível em $<$ http://php.iesb.br/ojs/index.php/psicologiaiesb/article/view/30/33>. Acesso em: 14 jul. 2012.

BRASIL. Lei no. 11.340, de 7 de agosto de 2006. Cria mecanismos para coibir e prevenir a violência doméstica e familiar contra a mulher. Diário Oficial da União, Brasília, 8 ago. 2006. Disponível em: <http://www.planalto.gov.br/CCIVIL/Ato2004-2006/2006/Lei/ L11340.htm>. Acesso em: 20 jun. 2012.

BUBER, M. Eu Tu. 10. ed. São Paulo: Centauro, 2006.

DAVOLI, C. "Aquecimento: caminhos para a dramatização". In: ALMEIDA, W. C. de (org.). 
Abritta, Stela Dalva; Roque, Fernanda Cunha Fontoura; Ramos, Maria Eveline Cascardo. A importância do acolhimento e do aquecimento em grupos sem demanda no contexto da Justiça

Grupos: a proposta do psicodrama. São Paulo: Ágora, 1999, p. 77-88.

FONTOURA, F. A violência no casal: uma análise a partir do grupo socioterapêutico de homens encaminhados pela justiça. Artigo de conclusão de curso. Graduação em Psicologia da Universidade Católica de Brasília. Brasília, 2009.

Poder e Empoderamento na intervenção socioterapêutica com grupos de homens encaminhados pela justiça: um caminho possível?. 6 mai. 2012. 43 p. Monografia de especialização em Psicodrama - Pontifícia Universidade Católica de Goiás e Centro de Psicodrama de Brasília. Brasília, 2012.

FONSECA FILHO, J. S. F. Psicodrama da loucura: correlações entre Buber e Moreno. São Paulo: Ágora, 1980.

MARRA, M. M.; FLEURY, H. J. (orgs.). Grupos: intervenção socioeducativa e método sociopsicodramático. São Paulo: Ágora, 2008.

MONTEIRO, R. F. Jogos dramáticos. São Paulo: Ágora, 1994.

MORENO, J. L. Psicoterapia de grupo e Psicodrama. São Paulo: Mestre Jou, 1974.

Psicodrama. São Paulo: Editora Cultrix, 1975.

Fundamentos do Psicodrama. São Paulo: Summus, 1983.

Quem sobreviverá? Fundamentos da Sociometria, Psicoterapia de Grupo e Sociodrama. V. II. Goiânia: Editora Dimensão, 1994a.

Quem sobreviverá? Fundamentos da Sociometria, Psicoterapia de Grupo e Sociodrama. V. III. Goiânia: Editora Dimensão, 1994b.

Quem sobreviverá? Fundamentos da Sociometria, da Psicoterapia de Grupo e do Sociodrama - edição do estudante. São Paulo: Editora Daimon, Centro de estudos do relacionamento, 2008.

; MORENO, Z. T. Psicodrama: terapia de ação \& princípios da prática. São Paulo: Daimon, 2006.

OSÓRIO, L. C. "Teoria sistêmica e da comunicação humana". In OSÓRIO L. C.; VALLE, M. E. P. Terapia de famílias: novas tendências. Porto Alegre: Artmed, 2002.

PERAZZO, S. Ainda e sempre psicodrama. São Paulo: Ágora, 1994.

RAMOS, M. E. C. “O Agir Interventivo e a Pesquisa-ação". In: MARRA, M. M.; FLEURY, H. J. (orgs.). Grupos: intervenção socioeducativa e método sociopsicodramático. São Paulo: Ágora, 2008, p. 45-55.

Homens e mulheres envolvidos em violência e atendidos em grupos socioterapêuticos: união, comunicação e relação. Revista Brasileira de Psicodrama. São Paulo: v. 21, n. 1, 2013. Disponível em: <http://pepsic.bvsalud.org/scielo.php? script=sci_arttext\&pid=S0104-53932013000100004\&lng=pt\&nrm=iso $>$. Acesso em: 15 fev. 2014.

; FONTOURA, F. "O gênero e a violência no casal”. In: GALINKIN, A. L.; SANTOS, C. (org.). Gênero e Psicologia Social interfaces. Brasília: Technopolitik, 2010, p. 527-556.

RAMOS, M. E. C.; SANTOS, C.; DOURADO, T. "Violência intrafamiliar: desvelando a face (oculta) das vítimas". In: LIMA, F. R.; SANTOS, C. (orgs.). Violência doméstica: vulnerabilidades e desafios na intervenção criminal e multidisciplinar. Rio de Janeiro: Lumen Juris, 2009. 
SANTOS, A. J.; CONCEIÇÃO, M. I. G. Espiral psicodramático: ciência e arte do aquecimento. Revista Brasileira de Psicodrama [on-line]. V. 22, n. 1, p. 54-64, 2014.

ZIMERMAN D. E. "O primeiro contato. A entrevista inicial. Os critérios de analisabilidade. O contrato". In: ZIMERMAN, D. E. Manual de técnica psicanalítica: uma re-visão. Porto Alegre: Artmed, 2004.

Recebido: 11/10/2015

Aceito: $21 / 03 / 2016$

Stela Dalva Abritta. Formada pelo Instituto de Educação Superior de Brasília (IESB). Pedagoga graduada pelas Faculdades Integradas do Triângulo (FIT) - MG. Pós-graduada em Psicodrama pelo Instituto de Pesquisa e Intervenção Psicossocial (Interpsi) e pela Pontifícia Universidade Católica de Goiás (PUC-GO). SQN 305, bloco H ap. 504, CEP 70737-080, Brasília, DF. Tel.: (61) 81739908.

Fernanda Cunha Fontoura Roque. Formada pela Universidade Católica de Brasília, Pósgraduada em Psicodrama pelo Instituto de Pesquisa e Intervenção Psicossocial (Interpsi) e pela Pontifícia Universidade Católica de Goiás (PUC-GO). Avenida Jacarandá, lote 10, Edifício Villa Lucci, ap. 1101, Águas Claras Sul, CEP 71927-540, Brasília, DF. Tel.: (61) 81022072 .

Maria Eveline Cascardo Ramos. Mestre em Psicologia pela Universidade de Brasília (1982). Professora ms-2 do Instituto de Pesquisa e Intervenção Psicossocial (Interpsi) e da Pontifícia Universidade Católica de Goiás (PUC-GO). Atua com ênfase nas áreas Social e Jurídica e nos Processos grupais e de comunicação. Pesquisadora nas áreas de Violência contra a mulher e de Violência contra crianças e adolescentes. Quadra 205, lote 09, bloco B, ap. 501, Águas Claras, CEP 71925 000. Brasília, DF. Tel.: (61) 91671310 